\title{
Application of Virtual Reality Teaching in Power Plant Electrical Part Courses
}

\author{
Aihua Jiang, Jun Long \\ Guangxi key Laboratory of Power System Optimization and Energy Technology, Guangxi University, \\ Nanning, 530004, China \\ Jiangaihua889@126.com
}

Keywords: Virtual reality technology; Electrical engineering major at colleges and universities; Teaching; Application.

\begin{abstract}
New experimental equipment and experimental methods are gradually increased with high-speed development of modern science and technology. Many colleges and universities have begun to focus on exploring various teaching reform approaches in order to cultivate talents through modern resources especially under current general background of education informatization, thereby producing a lot of teaching methods. Virtual reality technology is applied in teaching activities of electrical engineering major at colleges and universities, teaching contents can be displayed more vividly, students' efficiency to master knowledge and skills can be improved, thereby improving the teaching quality. The research in the paper is mainly based on current electrical engineering major teaching at colleges and universities. Application method of virtual reality technology in the teaching activities is explored, and it is expected that certain reference value can be achieved.
\end{abstract}

\section{Related overview of virtual reality technology}

\section{Concept of virtual reality technology}

So-called virtual reality technology mainly emphasizes a relatively high-end man-machine interface. It also can be believed that a relatively hot topic in current technology research field is usually called artificial environment or virtual reality technology. Technologies contained in virtual reality technology are mainly implemented around computers, such as artificial intelligence, computer graphics, multimedia technology, digital image processing, man-machine interface technology, sensor technology, etc. Virtual reality technology belongs to high integration of these technologies. It can provide users with a realistic 3D image world environment through simulation mode.

\section{Characteristics of virtual reality technology}

Immersive. Immersive refers that certain validity can be felt in virtual environment aiming at users under virtual reality technology. It is difficult to feel that users are located in a virtual environment generated by computers in virtual environment under virtual technology support from another level. They always have an immersive feeling as if every picture and every scene are real.

Interactivity. Scene sketched by virtual reality technology actually belongs to an analogue simulation of real world constructed by computer graphics. Users can realize interpersonal harmony aiming at operational degree of objects in virtual environment and natural degree of feedback obtained from environment. Interactive implementation should depend on relevant 3D interactive equipment greatly. Users can realize interaction of objects in real environment and virtual environment under such equipment support.

Imagination. So-called imagination refers that users can absorb knowledge in virtual world and environment according to own cognitive ability and feeling ability, thereby constructing some scenes which can not be easily discovered in real life. The scene only can be displayed in imagination. Therefore, users can explore and discover some more abstract problems or essence of matters which can not be easily discovered in the objective world through virtual reality technology, thereby discovering problem solutions. 


\section{Application of virtual reality technology in electrical engineering major teaching at colleges and universities}

\section{Compensation for disadvantages in traditional theory teaching}

Cultivation of innovative talents in colleges and universities is emphasized in new period. However, cultivation of innovative talents has closer link with innovative teaching implementation. It not only has innovation of teaching ideas and innovation of teaching contents, but also contains corresponding teaching methods, teaching means and teaching mode. The traditional teaching mode does not adapt to current student development demand at the macroeconomic level and under the background of rapid development of science and technology. Many modern teaching models are produced. Virtual reality technology belongs to a brand-new attempt. Because teachers often overemphasize theory and ignore the connection between practice and theory in traditional teaching, the studied subjects have certain technical character especially aiming at students in electrical engineering major, and students can understand of many contents through own experience. If teachers singly depend on traditional didactic teaching method, or simply adopt several multimedia pictures for teaching, it is obvious that knowledge can not be flexibly displayed in front of students. The above problems are properly solved by virtual reality technology. Electric engineering teaching mode can be separated from text and static principle diagram under the effect of the technology. The whole working process is dynamically displayed with stronger visual feeling. Students can be assisted for comprehending abstract knowledge, thereby stimulating their interest in learning.

Related content of AC/DC speed regulation in power plants is regarded as an example. When the content is taught, students are lack of understanding on system operation condition, and certain effect can not be obtained merely depending on text description. Therefore, role of parameters, influence in the whole system operation process, etc. can be simulated in teacher scene by the aid of virtual reality technology, thereby students can think from many perspectives.

\section{Reduction of expense and class hours}

There are more professional related skill training and some professional verification experiments during practice activities of electrical engineering major would at colleges and universities, the experiments can be supported by some experimental equipment, and teaching cost can be improved to certain extent. However, teaching expense is limited in teaching at colleges and universities. In addition, teaching concepts are backward; therefore most schools adopt experiment equipment at lower price. Comprehensive multi-functional equipment is rarely adopted due to expensive price. In addition, professional course teaching time is shrinking with constant advancement of teaching curriculum reform, and student practice time is limited. If the latest virtual reality technology is integrated in teaching, the confirmatory experiments in most courses can be displayed on computers. It is worth noting that most professional software has relatively low costs, even some software is free, and more cost investment is not needed. If the software is applied in teaching activities, advanced experiment expense can be used for purchasing multifunctional experimental equipment. In addition, since some schools have relatively limited aging feature in the aspects of university-enterprise cooperation, related interests problems are always involved in university-enterprise cooperation. Students can not actually obtain excellent effect easily. The problem can be properly solved by virtual reality technology under the precondition, thereby assisting students to reproduce the scene. Meanwhile, student management can be assisted if they study under the guidance of teachers, thereby improving learning efficiency, and lowering teaching cost.

\section{Virtual reality technology has higher safety}

Virtual reality technology is applied in teaching, which can effectively avoid various possible risks in real experiment. Some experiments with higher risk coefficient are always involved in previous teaching activities. For example, teachers mostly adopt the mode of TV video to replace corresponding experiment teaching in previous teaching activities aiming at teaching contents in the aspect of power plant. Teachers can not actually lead students to power plant or substation for feeling. However, experiments can be well implemented in virtual reality technology, thereby avoiding concerns of various security hidden dangers since students can complete various 
experiments more boldly and trustingly in virtual experiment, including some experiments with higher risk or experiments which are harmful to body health. For example, technology level of operators in substation has more significant significance in maintaining safety of power system in substation patrol and operating experience work. However, if students are not able to deeply understand the working process thereof, details of the work can not be actually comprehended. Therefore, $110 \mathrm{kv}$ substation is regarded as a virtual object for 3D modeling for equipment in the whole substation by means of virtual reality technology. Some invisible, untouchable and inaccessible dangerous places and equipment can be changed into accessible, visible and operational virtual scene through many situations such as roaming, patrol, operations, flight, bird's eye view, etc. Students can randomly browse and roam in the scenes. External form of equipment can be comprehended on one hand, and internal structures can be viewed on the other hand. It can be concluded that $3 \mathrm{D}$ reconstruction and virtual operation of substation primary equipment can be realized for achieving patrol operating experience similar to reality with more obvious intuition and visualization, further assisting students to understand scene situation. It also has interest and repeatability similar to game, and the learning enthusiasm of students can be greatly improved. Concrete conditions are shown in the following Fig. 1.
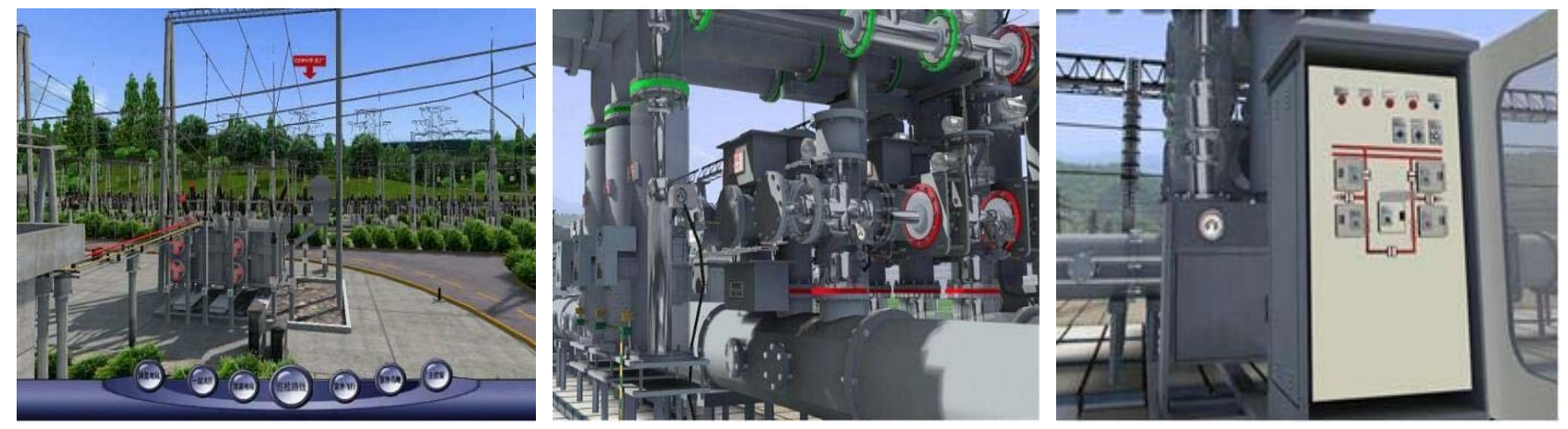

Fig.1. Three-dimensional reconstruction and virtual operating demonstration

\section{Application of virtual reality technology in electrical engineering major teaching at colleges and universities}

\section{Model of virtual reality technology}

The author proposes an experiment teaching application model of electrical engineering major at colleges and universities based on virtual technology as shown in the following figure according to characteristics of virtual reality technology.

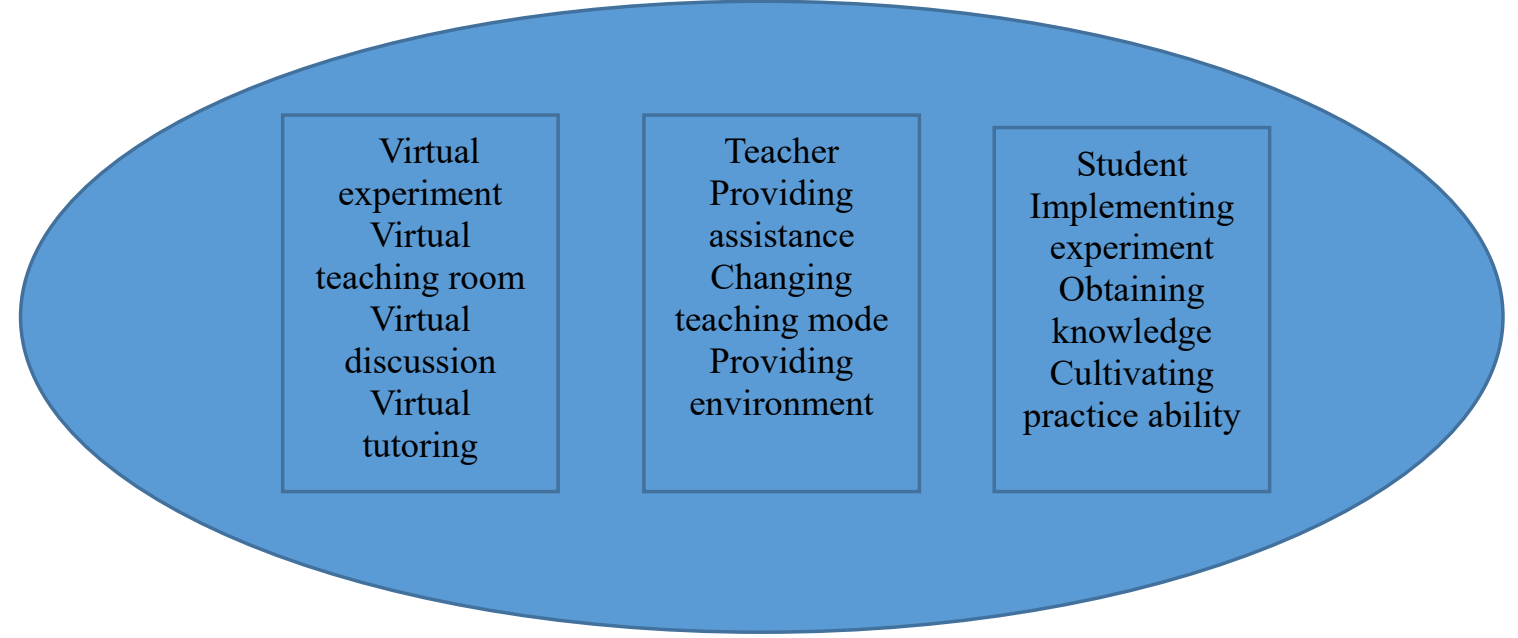

Fig.2. Simulation technology application model of teaching experience at universities and colleges

Teaching experiment platform at colleges and universities can be achieved through virtual reality technology, thereby providing teachers and students with a sound virtual experiment environment, mainly including the following aspects: 
Virtual experiment environment. Sound virtual environment can be provided for students in the model. Students can implement experiment operation in a realistic environment. Therefore, the diversified demands can be greatly satisfied. Of course, students can obtain information more actively under the environment. When professional ability is improved, sight can be widened, thereby stimulating students' subject enthusiasm and practice ability. The major is self-evident especially aiming at students in electrical engineering major, and substation is adopted as an example. Students not only can implement roaming, flight and bird's eye view for the whole substation on one hand, the contents are beyond the scope of textbook, which can broaden students' vision.

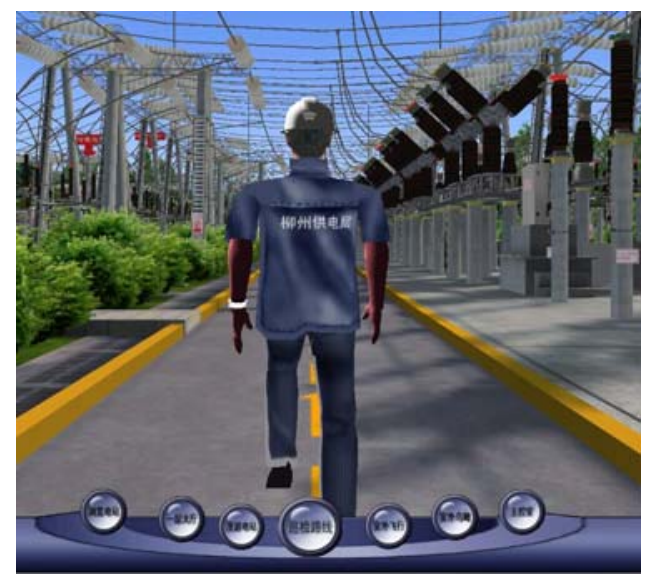

Fig.3. Virtual environment schematic diagram

Virtual teacher. The role of virtual teachers is irreplaceable and indispensable in the whole process of virtual experiment. Virtual teachers have main responsibility and task of navigation in the experiment. Students can be assisted to answer problems in tasks, and students can effective obtain learning resources, and improve learning quality. The contents about power plant and substation are more complicated, which are related to many circuits and techniques. It is difficult to exert actual value of virtual reality technology without guidance of virtual teacher.

Virtual experiment. Experiment is implemented in virtual environment. Virtual teachers can guide operation without actual arrival of teachers in the scene. Students can complete experiment through own efforts. Experiment effect can be achieved through assistance functions in the aspects of navigation, self-evaluation, self-test, etc. in the experiment system.

Electrical engineering major teaching at colleges and universities based on virtual reality technology

Virtual reality technology is more flexible in education teaching activities of electrical engineering major at colleges and universities. First of all, students can change matters according to learned theory knowledge and guidance of virtual teachers in the whole process of virtual experiment. Of course, the process is beneficial for students to analyze data according to own assumptions. In addition, students can validate experiment results and deepen understanding in the whole experiment process from the perspective of diversification aiming at experiment flexibility, thereby stimulating learning interest and ability. Secondly, emphasis on evaluation includes processing and experiment results of experimental data in the virtual experiment, comprehension of students on related fields and migration ability from virtualization to actual situation are involved under many occasions.

\section{Precautions in the process of virtual reality technology application}

Though it is observed in the previous description that virtual reality technology has fast, convenient, concise, vivid and other characteristics in electrical engineering teaching at colleges and universities, we have to admit that it still has many deficiencies which should be improved. For example, virtual reality technology is lack of physical sense. Power plant and substation course is adopted as an example. Students are in the situation created by virtual reality technology, both experimental apparatus and experimental equipment belong to false objects, which only can be observed and can not be perceived, thereby they are lack of physical sense. Teachers can lead 
students to view in power plants and substations for solving the problem. Then, virtual situation can be set, which is beneficial for students to tightly link virtualization to reality. In addition, since realistic experiment teaching has certain complexity itself, many factors are involved. Even if the operation is correct in real experiment, some abnormal phenomenon may be available, and the abnormal phenomenon is not available in the virtual situation, thereby limiting students' ability of strain. The author suggests that some emergencies can be appropriately integrated during situation setting for solving the problem, thereby cultivating students' ability of strain and thinking flexibility. Students' ability in analyzing and solving problems by themselves can be exercised.

\section{Conclusion}

Virtual reality technology has relatively broad application prospect with the arrival of information age. Its application in the field of education has especially been in the early stage, and there are larger potential and space. The author proposes the necessity of applying the virtual reality in the subject in the research of the paper. The case of power plant and substation is combined in the research process for describing, thereby proposing corresponding strategy. The research shows that virtual reality technology must depend on own powerful advantages and potential as novel teaching work, which can be widely applied in the field of education.

\section{Acknowledgement}

In this paper, the research was sponsored by the Teaching reform project of higher education in Guangxi 2015JB118(Project No. 2015JB118).

\section{References}

[1] Yao Jiangyun, Qi Baoqian. Application of virtual reality technology in electrical engineering course teaching reform [J]. Chinese Education Technology and Equipment, 2013,27:38-39.

[2] Su Min. Research on applying virtual reality technology in experiment teaching at colleges and universities [J]. China Education Informatization, 2011,07:66-67.

[3] Ju Lu. Virtual reality technology and application thereof in chemical teaching at colleges and universities [J]. Chemical Industry Management, 2016,01:125.

[4] Sun Qixin, Yang Jin, Xi Pingyuan. Application of virtual reality technology in mechanical professional course teaching [J]. Teachers, 2015, 35:92-93.

[5] Han Yang. Application of computer virtual reality technology in teaching at colleges and universities [J] Electronic Production, 2015, 10: 134.

[6] Zhang Ruifeng. Research on applying virtual reality technology in the electrical engineering major at secondary vocational schools [J]. Extracurricular Reading Periodical, 2011(11):50-50.

[7] Zhang Chunxian, Shan Chaolong, Wang Xiangjun. Application of virtual reality technology in circuit teaching $[\mathrm{C}] / /$ China Circuit and System Academic Annual Conference and Hong Kong and Macao Mainland Electronic Information Seminar in 2007.

[8] Zhang Tianyu. Virtual reality technology and its application in the teaching at colleges and universities [J]. Aerospace Computing Technology, 2012, 37(1):126-127.

[9] Ma Yuechao, Dong Ruihong. Application of virtual reality technology in classroom at colleges and universities. [J]. Science and Technology Information, 2014, 12(18):160-160.

[10] Yu Ping. Application of virtual reality teaching method in the course of electrotechnics [J]. Electronic World, 2016 (5):41-44. 